\title{
Effect of Ce cations on the crystallite size and pore structure genesis in nanostructured rutile after calcination
}

\author{
N. V. Shikina ${ }^{1}$, E. V. Bessudnova ${ }^{1}$, V. A. Ushakov ${ }^{1}$, A. P. Nikitin ${ }^{2}$, M. S. Mel'gunov ${ }^{1}$, \\ A. V. Ishchenko ${ }^{1}$, Z. R. Ismagilov ${ }^{1,2}$ \\ ${ }^{1}$ Boreskov Institute of Catalysis SB RAS, 5 Lavrentiev Ave., 630090, Novosibirsk, Russia \\ ${ }^{2}$ Institute of Coal Chemistry and Materials Science, Federal Research Center of Coal and Coal Chemistry SB \\ RAS, 18 Sovetskiy pr., 650000, Kemerovo, Russia \\ shikina@catalysis.ru
}

DOI 10.17586/2220-8054-2018-9-5-688-695

\begin{abstract}
A method for the low-temperature synthesis of titania with the 3D rutile nanostructure was developed, and the effect of introduced cerium ions on the thermal stability of the material was studied. According to XRD, TEM, Raman spectroscopy and BET data, the introduction of $3-10 \mathrm{wt} . \%$ Ce into the rutile matrix decreases the growth of nanorutile crystallites under the action of high temperatures ranging from $300-$ $1000{ }^{\circ} \mathrm{C}$ and provides the formation of a more porous structure in comparison with unmodified samples. Cerium cations are stabilized in the region of interblock boundaries or in the structural defects of rutile $\mathrm{TiO}_{2}$ and are released as the bulk $\mathrm{CeO}_{2}$ phase only at $1000{ }^{\circ} \mathrm{C}$, which does not exert a stabilizing effect at this temperature.
\end{abstract}

Keywords: titanium dioxide, nanostructured rutile, hierarchical architecture, porous structure, thermal treatment.

Received: 31 May 2018

Revised: 3 August 2018

\section{Introduction}

In recent years, the study of $\mathrm{TiO}_{2}$ hierarchical nanostructures has been a hot topic of research in the field of effective photocatalytic materials due to their high specific surface area, beneficial light absorption, and appropriate refractive index, along with other excellent physical and chemical properties [1-3]. The potent photocatalytic properties of $\mathrm{TiO}_{2}$ hierarchical nanostructures with rutile modification have been established in degradation of methyl orange, methylene blue and brilliant red $\mathrm{X}-3 \mathrm{~B}$ [4-7]. Rutile $\mathrm{TiO}_{2}$ has a high refractive index, which determines its application not only in photocatalysis but also in optical filters, protected printing and production of cosmetics and dyes [8].

Bulk rutile is the most stable phase among polymorphous modifications of titania (anatase, brookite and rutile). The formation of rutile from anatase or amorphous $\mathrm{TiO}_{2}$ species occurs after reaching a critical size of the particles and temperatures above $465{ }^{\circ} \mathrm{C}$. At the polymorphous transition temperatures the particles agglomerate and the specific surface area decreases below $7 \mathrm{~m}^{2} / \mathrm{g}$ [9]. The emphasis is now focused on the development of synthetic strategies for nanostructured titania that would permit its controllable three-dimensional formation. $\mathrm{TiO}_{2}$ synthesis under conditions leading to the formation of 3D structures with hierarchical packing of nanostructured particles makes it possible to obtain a material with the stable rutile phase and high specific surface area [10].

The properties of a composite hierarchical system are determined mostly by the properties of agglomerated particles, their packing and morphology, i.e. the texture of the material. Hierarchical rutile $\mathrm{TiO}_{2}$ microspheres assembled by nanowire bundles were synthesized upon hydrothermal conditions and then treated by thermally annealed in [4]. T. Yan and co-authors relate structural defects and high functional properties of rutile to the "microcavity" structure which existed between the roughly parallel nanowires of $\mathrm{TiO}_{2}$ microspheres. Upon annealing at 300 and $500{ }^{\circ} \mathrm{C}$ the microspherical shape was maintained, whereas the interface of the nanowire bundles became blurred and the related microstructural feature greatly changed. At $700{ }^{\circ} \mathrm{C}$, nanowires were converted into larger nanorods. The authors attribute such integration between quasi-parallel nanowires to a possible growth of crystals in the perpendicular direction. It is clear that the annealing treatment seriously destroyed the microcavity structure.

Our earlier studies [11-13] demonstrated the possibility of obtaining rutile with a hierarchical 3D nanostructure composed of fan-shaped nanofibers (specific surface area $>140 \mathrm{~m}^{2} / \mathrm{g}$ ) at atmospheric pressure and a temperature below $100{ }^{\circ} \mathrm{C}$. This revealed the control the main synthesis parameters (e.g. temperature, concentration of $\mathrm{Ti}^{4+}$ and $\mathrm{Cl}^{-}$ions) had on the formation of the rutile phase. However, the produced material has a low crystallinity and a high defect content and interblock boundaries, which determine the low stability of its textural properties after thermal treatment [14]. Changes in the morphology of the material were observed at the $300-400{ }^{\circ} \mathrm{C}$, lower than temperatures previously reported in [4]. The enhancement of thermal stability of the material is a topical task 
because textural characteristics of nanostructured rutile are of key importance for its application as a support of catalysts or photocatalysts.

In [15-17], titania was modified with different metal cations, shifting the anatase $\rightarrow$ rutile polymorphous transformations to higher temperatures, which is accomplished by inhibiting the growth of crystallites stabilized by $\mathrm{CeO}_{2}$ [15], $\mathrm{SiO}_{2}$ [16] or $\mathrm{Y}_{2} \mathrm{O}_{3}$ [17] interlayers. Such modification results in the formation of nanocrystalline anatase structure comprising incoherently intergrown particles; this significantly hinders the growth of anatase crystallites to the critical values at which anatase converts to rutile. In $[18,19]$ it was shown that modification with $\mathrm{La}$ and $\mathrm{Ce}$ ions [18] or $\mathrm{La}$ and $\mathrm{Mg}$ ions [19] stabilizes the alumina pore structure and specific surface area. The authors revealed a relation between the effect exerted by metal cations on polymorphous transformations in alumina and its structural-mechanical properties.

In the present work, we explored the possibility of decreasing rutile crystallite growth and preventing the deterioration of its pore structure parameters during thermal treatment upon modification of the initial low-temperature rutile samples with cerium cations. Since rutile is a stable phase of titania, it is evident that polymorphous transformations will not occur; however, the formation of the stabilizing ceria interlayers in nanostructured rutile may hinder the growth of nanofiber crystallites in the perpendicular direction.

\section{Experimental}

The method employed for the synthesis of nanostructured rutile is described in detail in [13]. Briefly, titania (rutile) was synthesized by the sol-gel method via the hydrolysis of titanium tetrachloride in water under the following conditions: molar ratios $\left[\mathrm{Cl}^{1-}\right] /\left[\mathrm{Ti}^{4+}\right]=4$ and $\left[\mathrm{H}_{2} \mathrm{O}\right] /\left[\mathrm{Ti}^{4+}\right]=39$, and the hydrolysis temperature of $90{ }^{\circ} \mathrm{C}$. To improve thermal stability, an aqueous solution $\mathrm{Ce}\left(\mathrm{NO}_{3}\right)_{3} \cdot 6 \mathrm{H}_{2} \mathrm{O}$ was deposited on the dried rutile powder by incipient wetness impregnation to obtain 3, 5, 7 and $10 \mathrm{wt} \% \mathrm{CeO}_{2}$ content in the final samples. After that, the samples with different $\mathrm{CeO}_{2}$ content were calcined at $300,500,700$ and $1000{ }^{\circ} \mathrm{C}$. A series of rutile samples modified with ceria was examined by XRD, BET, Raman spectroscopy and TEM. A rutile sample without $\mathrm{CeO}_{2}$ served as the reference sample.

The chemical compositions of the synthesized samples were estimated by inductively coupled plasma atomic emission spectroscopy on an Optima $4300 \mathrm{DV}$ instrument and by X-ray fluorescence analysis on an ARLAdvant'x analyzer with an Rh-anode X-ray tube. XRD studies were performed using an HZG-4C (Freiberger Präzisionsmechanik) X-ray diffractometer with a $\operatorname{CoK} \alpha$ monochromatic source $(\lambda=1.79021 \AA)$ in a continuous mode over the $2 \theta$ angular range from 20 to $85^{\circ}$. Crystallite sizes were estimated by the Scherrer formula. The measurement error is in the range of: $30-50 \pm 2 ; 50-80 \pm 5 ; 80-120 \pm 10 ; 120-180 \pm 25 ; 180-250 \pm 40$; $250-300 \pm 80 \AA$. Raman spectroscopy studies were carried out on a Renishaw Invia Basis spectrometer at $3600-$ $100 \mathrm{~cm}^{-1}$. Textural properties (specific surface area and pore volume) were analyzed by low-temperature nitrogen adsorption (ASAP-2400, Micromeritics) and mercury porosimetry (AutoPore IV 9500 V1.09, Micromeritics). The measurement error of textural parameters is $5 \%$. Transmission electron microscopy (TEM) and high resolution transmission electron microscopy (HR-TEM) images were obtained using a JEM-2010 (JEOL, Japan) microscope.

\section{Results and discussion}

Particles of the material obtained by $\mathrm{TiCl}_{4}$ hydrolysis belong to the rutile phase and have an intricate packing system; their characteristics correspond to those of 3D hierarchical structures. At the first structural level, the primary particles coherently inter-grow to form nanofibers. The oriented addition of the primary particles includes a spontaneous self-organization of adjacent particles due to which they become involved in the joint crystallographic orientation with subsequent agglomeration of the particles at the plane interface [20]. Binding of the particles decreases the total energy of their aggregates due to the surface energy of uncompensated bonds of primary particles, thus leading to the coherent intergrowth of particles, which is more favorable in terms of energy. Nanofibers forming the first structural level are joined into the fan-shaped aggregates that constitute the second structural level. At the third level the aggregates merge into large 3D particles [13].

\subsection{XRD}

X-ray diffraction (XRD) studies of the samples showed that the crystallite size of rutile is $55-70 \AA$ along the (110) direction and $140-200 \AA$ along (002) [11]. A clear dependence of crystallite sizes on the synthesis temperature was not observed. However, substantial changes in the crystallite size were revealed after calcination of the samples at $300,500,700$ and $1000{ }^{\circ} \mathrm{C}$ (Table 1). Upon calcination at $300-500{ }^{\circ} \mathrm{C}$ the crystallite size of rutile increased 2 - 3-fold, and calcination at 700 and $1000{ }^{\circ} \mathrm{C}$ resulted in the formation of large crystallites with the size greater than $1000 \AA$ along all crystallographic directions. Thus, calcination at temperatures above $700{ }^{\circ} \mathrm{C}$ does not produce noticeable changes in the XRD pattern of the samples. 
The rutile samples modified with cerium cations also showed an increase in the crystallite size upon calcination (Table 1). However, the crystallite size of the samples with $\mathrm{Ce}$ is much smaller in all crystallographic directions as compared to the rutile samples without cerium addition at a temperature up to $700{ }^{\circ} \mathrm{C}$. On diffraction patterns of the rutile samples modified with $3-10 \% \mathrm{CeO}_{2}$, the bulk ceria phase manifests itself only after calcination at $1000{ }^{\circ} \mathrm{C}$ (Fig. 1); at this temperature ceria does not exert a stabilizing effect. The crystallite size of the $1000{ }^{\circ} \mathrm{C}$ samples strongly exceeds $1000 \AA$ both in the modified rutile series and in the samples without additives. Peaks corresponding only to the rutile phase are observed on diffraction patterns of the samples calcined at $300-700{ }^{\circ} \mathrm{C}$. Peaks corresponding to the interaction phases in the Ce-Ti-O system were also not detected, and the crystal lattice parameters of rutile correspond to those of pure rutile. Supposedly, ceria is in a highly dispersed state and is located mostly on the surface of rutile crystallites, thus preventing their intergrowth upon calcination.

TABLE 1. Crystallite sizes of the calcined samples of nanostructured rutile with different ceria content

\begin{tabular}{|c|c|c|c|c|c|c|}
\hline \multirow[t]{2}{*}{$\mathbf{T}_{\text {calc }},{ }^{\circ} \mathbf{C}$} & \multirow[t]{2}{*}{$\mathrm{CeO}_{2}, \%$} & \multicolumn{5}{|c|}{ Crystallite sizes (E) along crystallographic directions } \\
\hline & & $\begin{array}{c}110 \\
32.00^{\circ}\end{array}$ & $\begin{array}{c}101 \\
42.19^{\circ}\end{array}$ & $\begin{array}{c}111 \\
48.30^{\circ}\end{array}$ & $\begin{array}{c}211 \\
64.09^{\circ}\end{array}$ & $\begin{array}{c}002 \\
74.45^{\circ}\end{array}$ \\
\hline After synthesis 90 & 0 & 60 & 130 & 120 & 70 & 165 \\
\hline \multirow[t]{5}{*}{300} & 0 & 125 & 200 & 190 & 140 & 230 \\
\hline & 3 & 95 & 170 & 170 & 100 & 230 \\
\hline & 5 & 70 & 170 & 170 & 95 & 230 \\
\hline & 7 & 70 & 170 & 170 & 95 & 230 \\
\hline & 10 & 70 & 170 & 170 & 95 & 230 \\
\hline \multirow[t]{5}{*}{500} & 0 & 190 & 250 & 240 & 200 & 250 \\
\hline & 3 & 140 & 200 & 200 & 130 & 250 \\
\hline & 5 & 110 & 200 & 200 & 150 & 250 \\
\hline & 7 & 110 & 200 & 200 & 150 & 250 \\
\hline & 10 & 110 & 200 & 200 & 150 & 250 \\
\hline \multirow[t]{5}{*}{700} & 0 & $\gg 1000$ & $\gg 1000$ & $\gg 1000$ & $\gg 1000$ & $\gg 1000$ \\
\hline & 3 & 220 & 400 & 300 & 160 & 190 \\
\hline & 5 & 180 & 270 & 300 & 160 & 190 \\
\hline & 7 & 170 & 210 & 270 & 150 & 200 \\
\hline & 10 & 170 & 180 & 250 & 150 & 200 \\
\hline \multirow[t]{5}{*}{1000} & 0 & $\gg 1000$ & $\gg 1000$ & $\gg 1000$ & $\gg 1000$ & $\gg 1000$ \\
\hline & 3 & $\gg 1000$ & $\gg 1000$ & $\gg 1000$ & $\gg 1000$ & $\gg 1000$ \\
\hline & 5 & $\gg 1000$ & $\gg 1000$ & $\gg 1000$ & $\gg 1000$ & $\gg 1000$ \\
\hline & 7 & $\gg 1000$ & $\gg 1000$ & $\gg 1000$ & $\gg 1000$ & $\gg 1000$ \\
\hline & 10 & $\gg 1000$ & $\gg 1000$ & $\gg 1000$ & $\gg 1000$ & $\gg 1000$ \\
\hline
\end{tabular}

\subsection{Raman spectroscopy}

Rutile has only three active modes in the Raman spectra: $145 \mathrm{~A}_{1 g}, 447 \mathrm{E}_{g}$, and $612 \mathrm{~B}_{1 g}$ [21]. Along with the indicated modes, a peak at ca. $240 \mathrm{~cm}^{-1}$, which can be assigned to the composite vibration, appears in the spectrum. Ceria has a cubic crystal structure of the fluorite type and manifests only one resolved combination mode, $465 \mathrm{~F}_{2 g}$ [22]. The Raman data obtained for the samples of pure rutile and rutile with the addition of $5 \%$ $\mathrm{CeO}_{2}$ are listed in Table 2. 




FIG. 1. The diffraction pattern of the rutile samples modified with $5 \% \mathrm{CeO}_{2}$ after their calcination at $300,500,700$ and $1000{ }^{\circ} \mathrm{C}$ (peaks corresponding to the $\mathrm{CeO}_{2}$ phase are marked by asterisks)

TABLE 2. Main and additional peaks of rutile in the Raman spectra

\begin{tabular}{|c|c|c|c|c|c|}
\hline $\begin{array}{c}T_{\text {calcination }}, \\
T_{\text {synthesis }}, \\
{ }_{\circ}{ }^{\circ} \mathrm{C}\end{array}$ & \multicolumn{4}{|c|}{$\begin{array}{l}\text { Position of main peaks / } \\
\text { Half-width, } \mathbf{c m}^{-1}\end{array}$} & $\begin{array}{l}\text { Additional peaks, } \\
\mathbf{c m}^{-1}\end{array}$ \\
\hline \multicolumn{6}{|c|}{ Rutile $+5 \% \mathrm{CeO}_{2}$} \\
\hline 100 & $141 / 5$ & $234 / 77$ & $444 / 45$ & $608 / 45$ & 822,1601 \\
\hline 300 & $142 / 4$ & $248 / 68$ & $424 / 71$ & $606 / 76$ & $169 / 12,1597$ \\
\hline 500 & $141 / 4$ & $242 / 92$ & $433 / 55$ & $607 / 63$ & $167 / 7,1599$ \\
\hline 700 & $141 / 5$ & $234 / 87$ & $442 / 43$ & $608 / 50$ & 821,1603 \\
\hline 1000 & $142 / 5$ & $234 / 87$ & $444 / 44$ & $609 / 45$ & 821,1606 \\
\hline \multicolumn{6}{|c|}{ Rutile } \\
\hline 90 & - & $239 / 63$ & $437 / 49$ & $605 / 55$ & 1601 \\
\hline 300 & $145 / 12$ & $234 / 67$ & $440 / 56$ & $608 / 54$ & 821,1601 \\
\hline 500 & $142 / 8$ & $233 / 81$ & $442 / 43$ & $609 / 48$ & 821,1602 \\
\hline 700 & $142 / 6$ & $231 / 89$ & 444 / 39 & $609 / 43$ & 819,1603 \\
\hline 1000 & $142 / 5$ & $231 / 87$ & 444 / 39 & $608 / 44$ & 824,1604 \\
\hline
\end{tabular}

For all the samples, the $\mathrm{B}_{1 \mathrm{~g}}$ peak did not change its position. In the case of rutile samples synthesized without $\mathrm{CeO}_{2}$, the half-width of the $\mathrm{B}_{1 g}$ peak decreased with raising the temperature from 55 to $43 \mathrm{~cm}^{-1}$, which testifies to the growth of crystallites. For the modified samples, at a calcination temperature of $300{ }^{\circ} \mathrm{C}$ the half-width of this peak increased from 45 to $76 \mathrm{~cm}^{-1}$, which indicates a decrease in the size of initial nanoparticles or a structural disordering with an increase in the bond length between atoms in the crystal lattice at the retained translational symmetry. This may occur due to intercalation of cerium cations between crystallites in the region of interblock boundaries where the rutile structure is strongly disordered, which makes the structural defects even more pronounced. As the temperature is raised to $1000{ }^{\circ} \mathrm{C}$, the half-width of the $\mathrm{B}_{1 g}$ peak decreases, similar to the case without $\mathrm{CeO}_{2}$. The main active vibration of $\mathrm{CeO}_{2}$ does not appear in the Raman spectra up to $1000{ }^{\circ} \mathrm{C}$. 
The most pronounced changes in the $\mathrm{E}_{g}$ peak of the modified Ce samples are observed upon calcination at $300{ }^{\circ} \mathrm{C}$ : the position of the peak shifts to the red region from 444 to $424 \mathrm{~cm}^{-1}$ with a simultaneous broadening of the band from 45 to $71 \mathrm{~cm}^{-1}$, which supports the assumption that defects in the nanoparticles increases, thus decreasing their sizes. A further increase in the temperature shifts the $\mathrm{E}_{g}$ peak to its initial value.

The Raman spectra of the modified samples after calcination at 300 and $500{ }^{\circ} \mathrm{C}$ show the peak at ca. $165 \mathrm{~cm}^{-1}$, which can be attributed to a minor decrease in the lattice symmetry. This vibration disappears at elevated temperatures, which testifies to restoration of the structure.

As seen in Table 2, at similar calcination temperatures the half-widths of all peaks of the modified samples are greater than the half-widths of peaks of the samples without $\mathrm{CeO}_{2}$; this testifies to a smaller size of the rutile particles with $\mathrm{CeO}_{2}$, which agrees with the XRD data.

\subsection{BET}

Investigation of the textural properties of rutile samples by low-temperature nitrogen adsorption revealed that in the entire range of temperatures the modified samples have a more developed pore structure with a higher specific surface area as compared to the zero sample (Table 3). All the samples with $\mathrm{CeO}_{2}$ and pure rutile that were calcined at 300 and $500{ }^{\circ} \mathrm{C}$ have comparable pore volumes that range from 0.1 to $0.13 \mathrm{~cm}^{3} / \mathrm{g}$. As the calcination temperature is raised, the pore volume values remain constant, whereas the specific surface area decreases and the average pore size increases; this testifies to implementation of the surface-diffusion sintering mechanism in the temperature range of $300-500{ }^{\circ} \mathrm{C}$ [15]. Pore broadening upon elevation of the calcination temperature from 300 to $500{ }^{\circ} \mathrm{C}$ is observed also on differential curves of the pore size distribution (Fig. 2). It should be noted that although the distribution curves are close to each other, the amount of thin pores with the effective diameter $3.5 \mathrm{~nm}$

TABLE 3. Pore structure parameters for nanostructured rutile samples with different $\mathrm{CeO}_{2}$ content

\begin{tabular}{|c|c|c|c|c|}
\hline$T_{\text {calc }},{ }^{\circ} \mathrm{C}$ & $\% \mathrm{CeO}_{2}$ & $\mathbf{A}_{B E T}, \mathrm{~m}^{2} / \mathrm{g}$ & $\mathrm{V}_{\Sigma}, \mathrm{cm}^{3} / \mathrm{g}$ & $\mathbf{D}_{\text {pore }}, \mathbf{n m}$ \\
\hline \multirow[t]{5}{*}{300} & 0 & 48.9 & 0.11 & 8.7 \\
\hline & 3 & 63.2 & 0.12 & 7.9 \\
\hline & 5 & 76.9 & 0.13 & 6.6 \\
\hline & 7 & 71.4 & 0.11 & 6.3 \\
\hline & 10 & 62.2 & 0.10 & 6.8 \\
\hline \multirow[t]{5}{*}{500} & 0 & 35.3 & 0.11 & 13 \\
\hline & 3 & 39.1 & 0.11 & 11.6 \\
\hline & 5 & 42.4 & 0.11 & 10.4 \\
\hline & 7 & 41.8 & 0.10 & 9.5 \\
\hline & 10 & 39.2 & 0.10 & 10.2 \\
\hline \multirow[t]{5}{*}{700} & 0 & 5.1 & 0.03 & 27.7 \\
\hline & 3 & 14.8 & 0.09 & 23.3 \\
\hline & 5 & 15.1 & 0.08 & 22.6 \\
\hline & 7 & 14.2 & 0.08 & 23.2 \\
\hline & 10 & 14.5 & 0.08 & 21.8 \\
\hline \multirow[t]{5}{*}{1000} & 0 & 1.2 & 0.005 & 16.2 \\
\hline & 3 & 2 & 0.006 & 11.7 \\
\hline & 5 & 2.2 & 0.005 & 9.7 \\
\hline & 7 & 2.1 & 0.006 & 11.9 \\
\hline & 10 & 2.1 & 0.01 & 21 \\
\hline
\end{tabular}


is greater in the modified samples than in pure rutile. Calcination at 700 and $1000{ }^{\circ} \mathrm{C}$ decreases both the specific surface area and the pore volume of all the samples; therewith, a decrease in the pore structure parameters for modified samples is less pronounced than for the calcined samples of pure rutile (Table 3). At $700{ }^{\circ} \mathrm{C}$ the specific surface area and pore volume of the samples with $\mathrm{Ce}$ are three times higher than the corresponding characteristics of pure rutile. The optimal ceria content in the samples is $5 \mathrm{wt} . \%$. A further increase in the $\mathrm{CeO}_{2}$ concentration does not produce an additional beneficial effect. At $1000{ }^{\circ} \mathrm{C}$ sintering of meso- and macropores occurs, the pore structure parameters are extremely low for all the samples, and these samples can be characterized as nonporous. The revealed regularities are clearly seen on differential curves of the pore size distribution for the series of 700 and $1000{ }^{\circ} \mathrm{C}$ samples (Fig. 2).


FIG. 2. Differential curves of the pore size distribution for the calcined rutile samples with different ceria content

\subsection{HRTEM}

High-resolution TEM images (Fig.3(a,b)) illustrate the intergrowth of pure rutile crystallites along interblock boundaries at $500{ }^{\circ} \mathrm{C}$ (Fig. 3(a)) and $700{ }^{\circ} \mathrm{C}$ (Fig. 3(b)). At $500{ }^{\circ} \mathrm{C}$, the pore structure formed by narrow slit-like pores is retained (the pores are marked by arrows in the Figure 3). At $700{ }^{\circ} \mathrm{C}$ the pores virtually disappear. A different pattern is observed for the rutile sample modified with $5 \% \mathrm{CeO}_{2}$ (Fig. 3(c,d)): the well developed pores between rutile crystallites are observed at both $500{ }^{\circ} \mathrm{C}$ (Fig. 3(c)) and $700{ }^{\circ} \mathrm{C}$ (Fig. 3(d)).

The TEM images also clearly demonstrate the difference in the crystallite sizes of rutile. The introduction of the Ce cation into the rutile matrix decreases the growth of its crystallites virtually by a factor of 2 . Between rutile particles one can see the interlayers of weakly crystallized ceria (Fig. 3(d), within the oval), which prevent the intergrowth of rutile crystallites along the interblock boundaries. Fig. 3 displays TEM images only for the samples calcined at 500 and $700{ }^{\circ} \mathrm{C}$, but this trend is observed also at other calcination temperatures.

It should be noted that the crystallized ceria phase was not detected in the samples calcined at $300-700{ }^{\circ} \mathrm{C}$ that were examined by XRD, Raman spectroscopy and TEM (using the measured interplanar distances). Most likely, titania inhibits the crystallization of ceria, which concentrates in the region of interblock boundaries of rutile 

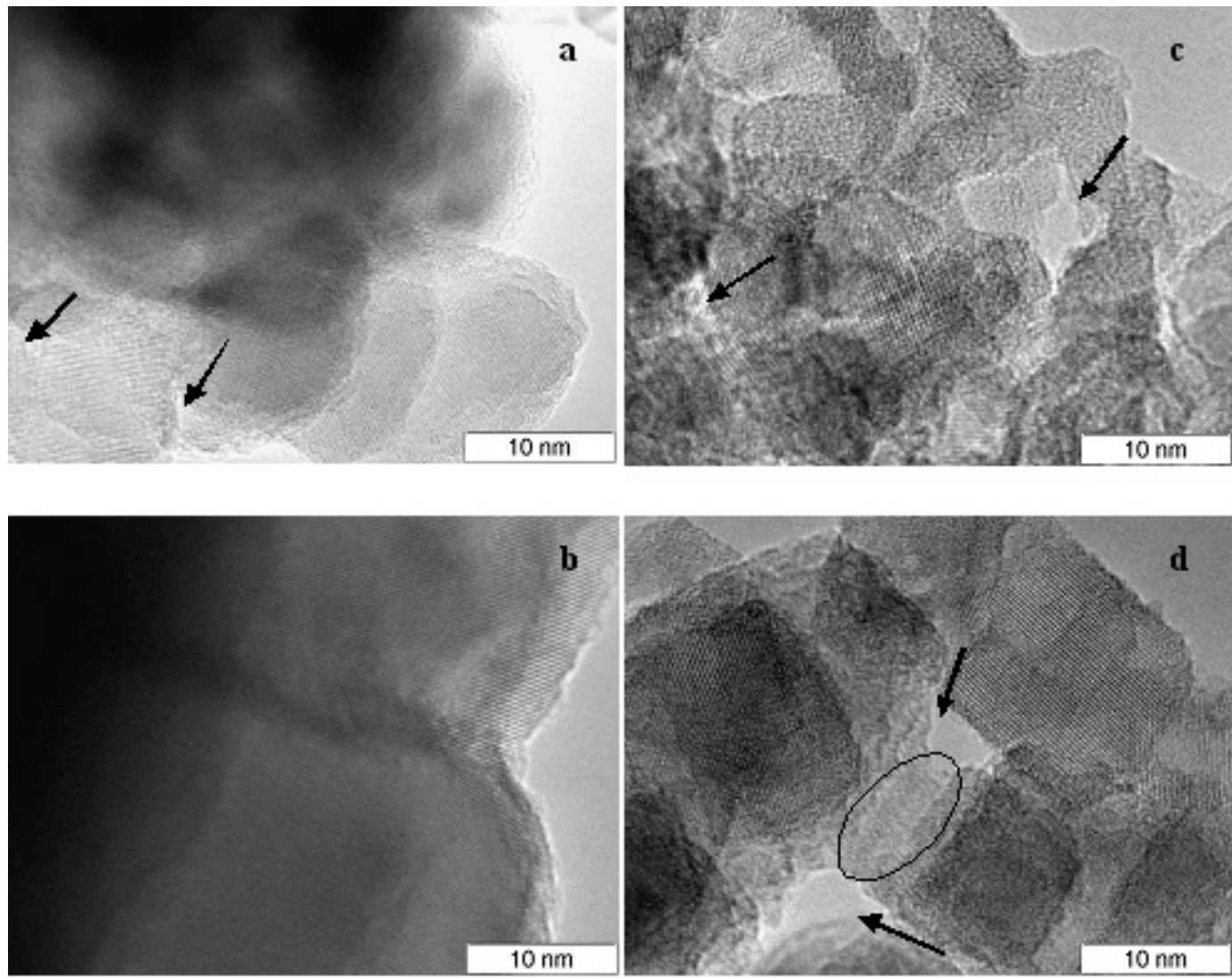

FIG. 3. High resolution TEM images of pure rutile samples calcined at 500 (a) and $700{ }^{\circ} \mathrm{C}$ (b) and rutile samples with the addition of $5 \% \mathrm{CeO}_{2}$ calcined at 500 (c) and $700{ }^{\circ} \mathrm{C}$ (d)

in the amorphized state. And only upon calcination at $1000{ }^{\circ} \mathrm{C}$ a part of cerium is released as an oxide from the region of interblock boundaries with the formation of surface $\mathrm{CeO}_{2}$ clusters and then the bulk $\mathrm{CeO}_{2}$ phase having the fluorite structure.

\section{Conclusion}

$\mathrm{TiO}_{2}$ (rutile) samples with the hierarchical 3D nanostructure were synthesized and modified with cerium cations; the effect of the modifying additive on the structural, textural and morphological properties of nanorutile was studied as a function of the calcination temperature. According to XRD, TEM, Raman spectroscopy and BET data, the introduction of $3-10 \mathrm{wt} . \%$ cerium into the rutile matrix decreases the growth of nanorutile crystallites at high temperatures ranging from $300-1000{ }^{\circ} \mathrm{C}$ and provides the formation of a more porous structure in comparison with unmodified samples. The optimal ceria content in the samples was found to be 5 wt.\%. A further increase in the $\mathrm{CeO}_{2}$ concentration does not produce an additional beneficial effect. Cerium cations are stabilized in the region of interblock boundaries or in the structural defects of $\mathrm{TiO}_{2}$ and are released as the bulk $\mathrm{CeO}_{2}$ phase only at $1000{ }^{\circ} \mathrm{C}$, which does not exert a stabilizing effect at this temperature.

\section{Acknowledgements}

This work was conducted within the framework of the budget project \# AAAA-A17-117041710090-3 for Boreskov Institute of Catalysis.

\section{References}

[1] Wu Z., Wu Q., et al. Progress in the synthesis and applications of hierarchical flower-like TiO 2 nanostructures. Particuology, 2014, 15, P. $61-70$.

[2] Liu W., Wang A., et al. Preparation and photocatalytic activity of hierarchically 3D ordered macro/mesoporous titania inverse opal films. Microporous and Mesoporous Materials, 2015, 204, P. 143-148.

[3] Chen P.C., Tsai M.C., et al. The "cascade effect" of nano/micro hierarchical structure: A new concept for designing the high photoactivity materials - An example for $\mathrm{TiO}_{2}$. Applied Catalysis B: Environmental. 2013, 142-143, P. 752-760. 
[4] Yan T., Yuan R., Li W., You J. Origin of superior photocatalytic activity in rutile $\mathrm{TiO}_{2}$ hierarchical microspheres: The dominate role of "microcavity" structure. Applied Catalysis A: General, 2014, 478, P. 204-210.

[5] Noh J., Yi M., et al. A facile synthesis of rutile-rich titanium oxide nanoparticles using reverse micelle method and their photocatalytic applications. Journal of Industrial Engineering Chemistry, 2016, 33, P. 369-373.

[6] Zhang J., Liu P., et al. One-step synthesis of rutile nano-TiO ${ }_{2}$ with exposed $\left\{\begin{array}{lll}1 & 1 & 1\end{array}\right\}$ facets for high photocatalytic activity. Journal of Alloys and Compounds, 2015, 632, P. 133-139.

[7] Li Y., Liu J., Jia Z. Morphological control and photodegradation behavior of rutile $\mathrm{TiO}_{2}$ prepared by a low-temperature process. Materials Letters, 2006, 60, P. 1753-1757.

[8] Pffaf G., Reynders P. Angle-Dependent Optical Effects Deriving from Submicron Structures of Films and Pigments. Chemical Reviews, 1999, 99, P. 1963-1981.

[9] Gribb A.A., Banfield J.F. Particle size effects on transformation kinetics and phase stability in nanocrystalline TiO ${ }_{2}$. American Mineralogist, 1997, 82, P. 717-728.

[10] Fattakhova-Rohlfing D., Zaleska A., Bein T. Three-Dimensional Titanium Dioxide Nanomaterials. Chemical Reviews, 2014, 114, P. 94879558.

[11] Ismagilov Z.R., Shikina N.V., Bessudnova E.V., Ushakov V.A. Effect of synthesis temperature on properties of nanoscale rutile with high surface area. Nanotechnologies in Russia, 2014, 9 (1-2), P. 21-25.

[12] Bessudnova E.V., Shikina N.V., Ismagilov Z.R. Nanoscale titanium dioxide synthesized by sol-gel method. International Scientific Journal for Alternative Energy and Ecology, 2014 , 7 (147), P. 39-47.

[13] Bessudnova E.V., Shikina N.V., Ismagilov Z.R. Synthesis and characterization of 3D hierarchical rutile nanostructures: Effects of synthesis temperature and reagent concentrations on the texture and morphology. Nanotechnologies in Russia, 2017,12 (3-4), P. 156-164.

[14] Shikina N.V., Bessudnova E.V., et al. Study of nanostructured $\mathrm{TiO}_{2}$ rutile with hierarchical 3-D architecture. Effect of the synthesis and calcinations temperature. Journal of Nanoscience and Nanotechnology, sent to the press.

[15] Zenkovets G.A., Shutilov A.A., et al. Formation of the structure of cerium oxide-modified titanium dioxide. Kinetics and Catalysis, 2007, 48 (5), P. 742-748.

[16] Zenkovets G.A., Gavrilov V.Yu., Shutilov A.A., Tsybulya S.V. Effect of silicon dioxide on the formation of the phase composition and pore structure of titanium dioxide with the anatase structure. Kinetics and Catalysis, 2009, 50 (5), P. $760-767$.

[17] Shutilov A.A., Zenkovets G.A., Gavrilov V.Yu., Tsybulya S.V. Effect of yttrium oxide on the formation of the phase composition and porous structure of titanium dioxide. Kinetics and Catalysis, 2011, 52 (1), P. 111-118.

[18] Koryabkina N.A., Shkrabina R.A., et al. Study of the Catalysts of Fuel Combustion. XVII. Effect of Lanthanum and Cerium on Structural and Mechanical Properties of Alumina. Kinetics and Catalysis, 1997, 38 (1), P. 112-116.

[19] Koryabkina N.A., Shkrabina R.A., Ushakov V.A., Ismagilov Z.R. Synthesis of a mechanically strong and thermally stable alumina support for catalyst used in combustion processes. Catalysis Today, 1996, 29 (1-4), P. 427-431.

[20] Penn R.L., Banfield J.F. Imperfect oriented attachment: dislocation generation in defect-free nanocrystals. Science, 1998, 281, P. 969-971.

[21] Handbook of Minerals Raman Spectra (ENS-Lyon). Free database 2000-2018. URL: www.ens-lyon.fr/LST/Raman/ spectrum.php?nom=rutile.

[22] Cui J., Hope G.A. Raman and Fluorescence Spectroscopy of $\mathrm{CeO}_{2}, \mathrm{Er}_{2} \mathrm{O}_{3}, \mathrm{Nd}_{2} \mathrm{O}_{3}, \mathrm{Tm}_{2} \mathrm{O}_{3}, \mathrm{Yb}_{2} \mathrm{O}_{3}, \mathrm{La}_{2} \mathrm{O}_{3}$, and $\mathrm{Tb}_{4} \mathrm{O}_{7}$. Journal of Spectroscopy, 2015, 2015, 940172. 